\title{
MEDIA SOSIAL INSTAGRAM SEBAGAI PRESENTASI DIRI PADA MAHASISWI PENDIDIKAN SOSIOLOGI FKIP UNTIRTA
}

\author{
Rizki Setiawan $^{1}$, Nurul Audie ${ }^{2}$ \\ Dosen Pendidikan Sosiologi Universitas Sultan Ageng Tirtayasa \\ Mahasiswi Pendidikan Sosiologi Universitas Sultan Ageng Tirtayasa \\ rizkisetiawan@untirta.ac.id ${ }^{1}$, nurulaudies@,gmail.com ${ }^{2}$
}

\begin{abstract}
Social media is one platform for presenting individuals. Instagram is a social media chosen to present an individual compared to other social media. This study aims to find out how Untirta Educational Sociology students present themselves on Instagram, why Untirta Educational Sociology students choose Instagram social media to present themselves compared to other social media. This study uses qualitative research with descriptive research methods, and data collection techniques through in-depth interviews with informants. The theory used in this study is the Dramaturgy Theory by Erving Goffman. This research explains about dramaturgy which is done on Instagram which consists of front stage and back stage. The informants in this study were two active users of Instagram in Untirta's Sociological Education. The results of this study are students of Educational Sociology Untirta using filters, feeds, uploading photos or videos, and uploading Instastory to present themselves well on Instagram and choosing Instagram because Instagram is a popular social media compared to other social media.
\end{abstract}

Keywords: Instagram, social media, self presentation

\section{PENDAHULUAN}

Istilah 'presentasi diri atau 'self presentation' pertama kali dikemukakan oleh seorang sosiolog yang berasal dari Kanada bernama Erving Goffman dalam bukunya yang berjudul 'The Presentation of Self in Everyday Life' (Ritzer and Goodman, 2012). Setiap individu memiliki caranya masing-masing untuk mempresentasikan diri mereka untuk memberikan kesan positif terhadap penilaian orang lain.

Media massa merupakan sebuah alat komunikasi dan informasi yang digunakan untuk penyebaran secara menyeluruh dan dapat diterima oleh masyarakat secara bersamaan (Syukriardi, 2015). Internet merupakan salah satu contoh dari media massa, karena pesan yang diterima melalui internet dapat diterima oleh banyak orang. Dikutip dari gatra.com, Kominfo menyebutkan hingga Juni 2019, Indonesia memiliki 181 juta 
Community: volume 6, nomor 1, April 2020

p-ISSN: 2477-5746 e-ISSN: 2502-0544

pengguna internet. Efek dari penggunaan media massa dapat dilihat dari perubahan pengetahuan, sikap dan tingkah laku (Syukriardi, 2015).

Pada media sosial, pengguna tidak memiliki batasan untuk mempresentasikan atau menampilkan diri mereka. Salah satu media sosial yang digunakan untuk mempresentasikan diri ialah Instagram. Media sosial seperti Instagram dapat membentuk visualisasi seseorang dengan segala aktivitasnya (Kertamukti, 2015). Instagram dapat dikatakan sebuah media sosial untuk mempresentasikan diri yang paling fenomenal diantara media sosial lainnya seperti facebook, twitter, dan sebagainya. Hal ini dibuktikan sesuai dengan yang dituliskan di tagar.com, Indonesia memiliki jumlah Instagram User terbanya keempat didunia. Hampir dari seperempat populasi penduduk Indonesia menggunakan Instagram untuk mempresentasikan diri mereka. Perusahaan analisis Social Media Marketing mencatat bahwa jumlah pengguna Instagram di Indonesia per November 2019 sebanyak 61.610 .000 juta pengguna yang terdiri dari 50,8\% perempuan dan 49,2\% laki-laki.

Presentasi diri berkembang secara cepat semenjak munculnya media sosial. Para pengguna media sosial memiliki cara yang berbeda-beda mempresentasikan dirinya terhadap orang lain, bisa dengan cara bentuk nyata ataupun tidak. Seperti presentasi diri yang tak kasat mata terlihat dari menuliskan kata-kata bijak di tweets. Individu dapat menampilkan sebuah pertunjukkan kepada banyak orang, tetapi kesan yang didapatkan dapat berbeda-beda (Fitri, 2015). Ketika individu sedang berinteraksi, mereka ingin mempresentasikan sebaik mungkin agar dapat diterima orang lain, karena orang lain memiliki potensi untuk mencetak siapa diri kita sehingga setidaknya kita dapat mengasumsikan apa yang orang lain asumsikan tentang diri kita (Putri, 2016).

Ketika melakukan interaksi secara tatap muka, presentasi diri individu lebih memiliki batasan karena bisa saja dapat dibantah oleh indvidu lain jika bertatapan secara langsung, tetapi di media sosial, individu tidak memiliki batasan untuk mempresentasikan diri mereka sehingga mereka dapat berusaha lebih baik dalam mempresentasikan diri sesuai apa yang mereka mau, karena individu lain tidak hadir untuk mengkritik ataupun membantah penampilan mereka secara langsung. Identitas seseorang dapat berubah tergantung dengan siapa individu berinteraksi (Sri Suneki and Haryono, 2012). Semakin berkembangnya Instagram di masyarakat, banyak individu yang menggunakam Instagram untuk berbagai kepentingan, ada yang menggunakannya untuk mempresentasikan dirinya, bahkan ada juga yang menggunakannya untuk berbisnis.

Media sosial Instagram adalah salah satu media sosial yang mempresentasikan diri penggunanya dalam bentuk video, gambar atau foto (Dewi and Janitra, 2018). Kebebasan individu dalam berpendapat dan berkespresi adalah hak individual sekaligus kolektif, orang memiliki kesempatan untuk menyampaikan, mencari,menerima dan mengeskpresikan pandangan mereka dengan cara apa yang menurut mereka tepat 
12

Community: volume 6, nomor 1, April 2020

p-ISSN: 2477-5746 e-ISSN: 2502-0544

(Setiawan, 2017). Di Instagram, para pengguna Instagram mempresentasikan dirinya sebaik mungkin untuk menunjukkan eksistensi dirinya agar mendapatkan likes yang banyak dari pengguna yang lain (Hartawan, 2017).

Pengguna Instagram termasuk kedalam masyarakat yang hendak berbagi dan mempunyai konsep diri tersendiri untuk memerankan peran-peran tertentu dalam masyarakat (Kertamukti, Nugroho and Wahyono, 2019). Dalam teori Dramaturgi, Goffman menganalogikan interaksi individu seperti panggung teater (Ritzer and Goodman, 2012). Didalam panggung teater, terdapat dua panggung yaitu front stage (panggung depan) atau back stage (panggung belakang). Pada sisi front stage, individu mempresentasikan sebaik mungkin agar mendapatkan citra yang baik terhadap orang lain, seperti halnya pemain drama menggunakan pakaian bagus, menghapal teks untuk menampilkan teater yang bagus. Ketika individu berada didunia nyata, yang terlihat adalah sifat yang sebenarnya atau disebut dengan back stage. Seperti apa yang para aktor tampilkan, aktor tersebut mempresentasikan dirinya, membawakan perannya sebaik mungkin, mengasumsikan karakternya, dan bermain melalui adegan-adegan ketika terlibat dalam interaksi dengan orang lain (Mutia, 2018).

Pada media sosial Instagram terjadi fenomena individu hanya menampilkan citra baiknya saja di media sosialnya, dan menutupi citra buruknya, fenomena ini membuktikan bahwa terjadinya dramaturgi ketika bermain Instagram. Dalam Instagram, pengguna Instagram hanya menampilkan kesan-kesan yang baik saja. Hal ini disebut dengan Manajemen Kesan, atau seperti membut scenario (Ritzer and Goodman, 2012).

Berdasarkan pendahuluan yang telah dituliskan diatas, maka dirumuskan judul penelitian ini adalah: "Media Sosial Instagram Sebagai Presentasi Diri Pada Mahasiswi Pendidikan Sosiologi Untirta". Rumusan masalah didalam penelitian ini ialah, "Bagaimana Mahasiswi Pendidikan Sosiologi Untirta mempresentasikan diri di media sosial Instagram?". Sehingga tujuan dari penelitian ini adalah untuk mengetahui bagaimana Mahasiswi Pendidikan Sosiologi Untirta mempresentasikan diri di media sosial Instagram.

\section{TINJAUAN PUSTAKA}

\subsection{Komunikasi Massa}

Komunikasi massa ialah pesan atau informasi yang diberitahukan melalui media massa (media cetak atau elektronik) pada sejumlah populasi orang (Syukriardi, 2015). Komunikasi massa dapat membentuk opini publik dan memberikan kesamaan makna terhadap pesan yang telah diterima karena komunikasi massa menginfokan suatu informasi kepada banyak orang. Komunikasi massa memiliki karakteristik tersendiri, beberapanya adalah seperti dibawah berikut (Syukriardi, 2015): 
Community: volume 6, nomor 1, April 2020

p-ISSN: 2477-5746 e-ISSN: 2502-0544

a. Komunikator Melembaga

Dalam komunikasi massa, yang dimaksud dengan komunikator adalah banyak orang. Sehingga komunikator dalam komunikasi massa terdiri dari beberapa lembaga dan bekerja satu sama lain. Komunikator dalam komunikasi massa adalah media massa.

b. Komunikan Berupa Anonim dan Heterogen

Pengguna media massa terdiri dari berasal dari pendidikan, jenis kelamin, status sosial, ekonomi, dsb yang berbeda-beda. Dalam komunikasi massa, komunikan tidak mengetahui kepada siapa ia akan memberikan pesan atau disebut anonim, karena komunikan memberikan informasi melalui media dan tidak berinteraksi secara langsung atau tatap muka.

c. Menerima Pesan Secara Bersamaan.

Dalam komunikasi massa, khalayak mendapatkan pesan atau media informasi secara bersamaan walaupun didaerah atau pada jarak yang jauh.

\subsection{New Media}

Media massa semakin canggih seiring berkembangnya zaman, hal inilah yang melatarbelakangi munculnya istilah new media atau media baru. Media baru atau New Media merupakan segala sesuatu yang dapat menyalurkan informasi dari sumber informasi kepada penerima informasi tersebut. Media baru memiliki manfaat tersendiri bagi penggunanya, seperti mendapatkan informasi dengan cepat dan mudah diakses dimana saja, dan untuk berbisnis atau transaksi jual beli.

\subsection{Media Sosial}

Media sosial terdiri dari dua kata yaitu media dan sosial. Media artinya adalah sebuah alat komunikasi seperti koran, radio, televisi, film, dan media yang lainnya (kbbi.kemdikbud.go.id). Kata sosial artinya berhubungan dengan masyarakat (kbbi.kemdikbud.go.id). Dari pengertian diatas dapat disimpulkan bahwa media sosial adalah sebuh alat komunikasi yang berhubungan dengan masyarakat. Di zaman sekarang, terdapat banyak sekali media sosial yang tersedia, seperti whatsapp, line, facebook, instagram, twitter, dan masih banyak lagi.

\subsection{Dramaturgi}

Dalam teori dramaturgi yang dikemukakan oleh Goffman, Goffman menggambarkan bahwa interaksi individu ibaratkan seperti sebuah teater yaitu terdiri dari front stage (panggung depan) dan back stage (panggung belakang. Pada front stage, terdapat adanya 'setting', dekorasi, atau hal-hal yang dapat mendukung penampilannya di front stage) (Goffman, 1956). Dramaturgi menjelaskan bahwa ketika manusia berinteraksi, manusia dapat memilih peran apa yang akan dijalankan, seperti itulah 
14

Community: volume 6, nomor 1, April 2020

p-ISSN: 2477-5746 e-ISSN: 2502-0544

individu ketika berada di front stage untuk mendapatkan citra yang baik terhadap individu yang melihatnya. Pengguna Instagram berusaha sebaik mungkin untuk menerima kesan yang diharapkannya sehingga melakukan berbagai cara untuk mendapatkan likes dan followers yang banyak. Dalam back stage, individu menampilkan dirinya yang sebenarnya karena individu tidak mengharapkan kesan terhadap penampilannya, seperti pengguna Instagram mengunggah Instastory sedang tertawa bahagia tetapi bisa saja dalam kehidupan aslinya malah sebaliknya.

\section{METODE PENELITIAN}

Penelitian ini menggunakan jenis penelitian kualitatif dengan metode deskriptif. Metode penelitian kualitatif adalah metode penelitian yang merujuk kepada aliran postpositivisme, yang digunakan untuk meneliti pada suatu obyek yang alamiah, dan peneliti adalah sebagai instrument kunci, teknik pengumpulan data dilakukan dengan gabungan, analisis data bersifat umum ke khusus dan kualitatif, dan hasil penelitian kualitatif lebih menekankan makna daripada generalisasi (Sugiyono, 2017).

Peneliti mendapatkan informasi dan mengumpulkan data secara mendalam pada sebuah fenomena sosial yang terjadi, yaitu media sosial instagram sebagai presentasi diri di kalangan mahasisiwi Pendidikan Sosiologi Untirta. Penelitian ini bertujuan untuk mengetahui bagaimana mahasiswi Pendidikan Sosiologi Untirta mempresentasikan dirinya melalui Instagram dan mengapa mereka memilih Instagram sebagai tempat mempresentasikan diri dibandingkan dengan media sosial yang lainnya. Penelitian dilakukan di Kampus C FKIP Untirta Kota Serang dan melalui chat whatsapp kepada satu informan lainnya. Dipilihnya Kampus FKIP Untirta untuk penelitian ini karena merupakan tempat yang memudahkan untuk bertemu dengan informan. Waktu yang diperlukan untuk penelitian ini kurang lebih seminggu dimulai dari tanggal 27 Februari hingga 4 Maret 2020.

Fokus penelitian ini adalah Instagram sebagai tempat untuk presentasi diri dikalangan mahasiswi Pendidikan Sosiologi Untirta . Penelitian ini menggunakan teknik pursposive sampling untuk memilih informan. Pursposive Sampling adalah cara pengambilan sample untuk sumber data penelitian dengan tujuan dan pertimbangan tertentu. (Sugiyono: 2017). Teknik pengumpulan data pada penelitian ini menggunakan data primer yaitu dengan cara observasi dan wawancara mendalam untuk mendapatkan informasi dari narasumber yang bersangkutan dan data sekunder yaitu informasi yang berkaitan dengan penelitian, berasal dari literatur buku, jurnal.

Teknik analisis data yang digunakan dalam penelitian ini adalah, pertama, reduksi data (data reduction): Pengumpulan informasi yang terkait dengan penelitian, data dikategorikan sesuai tema masalah. Kedua, pengumpulan data (data collection): Data yang dikelompokkan disusun dalam bentuk narasi, sehingga terbentuk menjadi sebuah informasi yang sesuai dengan penelitian. Ketiga, penyajian data (data display): 
Community: volume 6, nomor 1, April 2020

p-ISSN: 2477-5746 e-ISSN: 2502-0544

Melakukan interpretasi data yang telah didapatkan tentang masalah yang diteliti. Keempat, penarikan kesimpulan (conclusion drawing): Melakukan pengambilan kesimpulan dari data yang didapatkan. Kelima, evaluasi (evaluation): melakukan verifikasi hasil analisis data dengan informan yang diambil dari tahap penarikan kesimpulan Teknik validitas data yang digunakan dalam penelitian ini adalah triangulasi sumber. Triangulasi sumber dilakukan dengan cara mengecek data yang didapatkan dari beberapa sumber.

\section{HASIL DAN PEMBAHASAN}

Berdasalkan hasil pengamatan dan wawancara dengan para pengguna Instagram di FKIP Untirta, Instagram merupakan salah satu media sosial tempat mempresentasikan diri dan tempat berkomunikasi dengan teman, keluarga, sahabat, maupun public figure pada Instagram. Selain menjadi tempat untuk mempresentasikan diri, dengan cara meng-follow akun-akun penting seperti berita, pengguna Instagram mendapatkan informasi-informasi terbaru.

Berdasarkan dari hasil observasi dilapangan dengan para pengguna Instagram di FKIP Untirta, banyak cara untuk mempresentasikan diri mereka di Instagram yaitu sebagai berikut:

\section{Mengupload/mengunggah foto ke Instagram.}

Menurut Instagrammer di FKIP Untirta, mereka sebelum mengeupload atau menggunggah foto ke Instagram, diadakannya seleksi terlebih dahulu terhadap foto yang akan diupload. Mereka memilih mana yang lebih layak diupload, kemudian mereka meng-edit sebagus mungkin menggunakan aplikasi editor seperti Lightroom, PicsArt, Unfold, Tezza, Vsco dan aplikasi editor lainnya untuk menarik perhatian para followers akun Instagramnya agar mendapatkan likes yang banyak. Mendapatkan likes yang banyak merupakan salah satu tujuan mengunggah foto ke Instagram, karena mendapatkan likes yang banyak dapat menjadikan Instagrammer terkenal atau yang sering disebut dengan Selebgram.

\section{Membuat feeds akun Instagram.}

Banyak penggunaan Instagram zaman sekarang, mengatur feeds Instagramnya sebagus mungkin.. Banyak aplikasi yang membantu untuk membuat feed instagram menjadi bagus atau istilahnya feeds planner seperti Unum. Maksud membuat feeds Instagram ini seperti memberikan pola terhadap foto-foto yang diupload, sehingga tidak mengupload foto dengan gaya yang sama dalam beberapa kali. Biasanya pengguna Instagram mengupload foto yang senada sebanyak tiga kali agar terlihat rapi dalam satu barisnya. Pada umumnya, 
jika mengatur feed instagram, foto yang diupload dengan menggunakan pola objek, selfie, quotes, ootd dengan bergantian. Alasan para pengguna instagram menggunakan feeds dalam akunnya ialah agar akun instagramnya enak dilihat dan agar pengguna lain meng-follow akun instagramnya.

\section{Mengupdate Instastory dan Instalive.}

Perbedaan Instastory dan Instalive dengan feeds instagram ialah, fitur ini hanya bisa dilihat selama 24 jam, dan sebagai pengguna instagram kita dapat melihat siapa-siapa saja yang telah melihat instastorynya, jika telah melebihi 24 pihak Instagram akan otomatis menghapusnya dan tidak dapat dilihat lagi . Untuk fitur Instalive, sama halnya dengan live streaming. Instalive dapat dilihat jika pengguna Instagram mengaktifkan live di Instagramnya. Instalive tidak ada batasan waktu, dan bisa menyimpannya dalam bentuk Instastory dalam waktu 24 jam. Berdasarkan dari hasil observasi lapangan, pengguna Instagram di FKIP Untirta biasanya mengupload Instastory dalam bentuk selfie, object pemandangan ketika berpergian. Alasan pengguna Instagram mengupload ketika berpergian untuk memberitahu kepada followersnya kalau mereka sedang pergi kesuatu tempat yang bagus seperti tempat wisata, cafe-cafe yang estetik, dan kadang mengunggah foto makanan.

\section{Penggunaan filter dalam mengupload Instastory}

Filter Instagram ini sendiri terbagi-bagi menjadi beberapa kategori, seperti Moods, Funny, Scenery, Colour, dan lain lain. Berdasarkan hasil observasi peneliti, para pengguna Instagram menggunakan filter untuk mempercantik diri, karena filter tersebut menambahkan efek tambahan seperti efek preset, emoji-emoji, dan beauty filters. Tetapi beberapa pengguna lain menggunakan filter hanya iseng aja, karena pengguna Instagram tersebut menggunakan filter yang berkategori funny, seperti contohnya filter bajaj, biskuit khong guan, dan lain lain. Cara pemakaiannya pun mudah, yaitu buka ikon Instastory, kemudian pilih filter yang akan dipakai.

\section{Jumlah likes dan followers mempengaruhi presentasi diri di Instagram.}

Berdasarkan hasil observasi dilapangan, jumlah likes dan followers mempengaruhi presentasi diri di Instagram. Memiliki followers dan likes likes yang banyak di Instagram mempengaruhi popularitas di Instagram. Jika menggunakan Instagram, likes dan followers bukan hanya sekedar angka yang 
Community: volume 6, nomor 1, April 2020

p-ISSN: 2477-5746 e-ISSN: 2502-0544

tercantum dalam Instagram. Tetapi, jika memiliki jumlah followers dan likes yang banyak, akan membuat pengguna Instagram popular. Banyak cara untuk mendapatkan likes dan followers yang banyak, dari mengupload foto yang estetik, dan membuat konten $I G T V$.

Karena menggunakan media sosial instagram, tidak jarang para pengguna memiliki rasa ingin menjadi terkenal. Untuk menjadi terkenal atau popular di instagram, para pengguna Instagram di FKIP Untirta melakukan berbagai cara, seperti menggunakan hashtag atau tagar untuk mendapatkan likes yang banyak. Selain itu, para pengguna Instagram melakukan hal hal yang sedang ngetrend agar dianggap mengikuti zaman dan mendapatkan likes yang banyak juga. Seperti mendatangi cafe-cafe yang Instagramable, befoto Outfit of The Day (OOTD) yang hits, dan juga memperindah feeds akun Instagramnya untuk menarik para followersnya. Feeds Instagram merupakan halaman akun pengguna Instagram Instagram yang berisikan dengan foto atau video yang diupload. Biasanya pengguna Instagram mengupload foto tiga foto sekaligus yang senada agar terlihat rapi.

Ada pengguna Instagram lebih nyaman mempresentasikan dirinya dengan mengupload Instastory dibandingkan dengan mengupload foto di akun Instagramnya. Seperti yang diungkapkan oleh Informan A ketika wawancara via Whatsapp:

"Aku kalau untuk mengupload foto jarang ka, perbulan kalau upload foto. Tapi kalau snapgram sering. Soalnya kalau snapgram cuma bisa dilihat 24 jam aja, setelah itu hilang jadi ga terus-terusan dilihat. Kalau upload foto aku kadang gak pede, kalau uploadnya lama terus ngelihatnya baru-baru ini kan kayak fotonya old banget. Beda sama gaya sekarang sama zaman sekarang jadi kaya mending hapus karena ngerasanya cakep pas dizamannya tapi ga aesthetic di zaman sekarang ka wkwk." (Wawancara via Whatsapp, 3 Maret 2020)

Pengguna Instagram menyeleksi foto apa yang akan diupload di Instagram agar sebagai galeri, kadang mengupload foto sebulan atau dua bulan sekali, karena pengguna Instagram sangat menyeleksi foto yang akan diupload agar feedsnya terlihat bagus dan enak dilihat. Pengguna Instagram biasanya mengunggah foto ditempat-tempat wisata, foto pakaian yang digunakan atau yang dikenal dengan istilah Outfit of The Day, tetapi lain hal bagi Instastory, kadang bahkan update berulang kali dalam sehari dikarenakan hanya dapat dilihat dalam waktu 24 jam. Hal ini diungkapkan oleh Informan B ketika wawancara di FKIP Untirta:

"Ga terlalu sering sih upload foto, kalau pergi-pergi doang diupload. Kalau foto pas dirumah ngapain diupload, gapenting. Biasanya perberapa bulan aku upload fotonya. Tapi kalau upload snapgram ga tiap hari, paling 3 hari sekali atau 4 hari sekali. Misalnya dalam sehari aku udah update, pasti pengen lagi buat ngeupdate, jadi biasanya 5 kali update. Kalau udah kosong ya kosong banget." (Wawancara, 4 Maret 2020) 


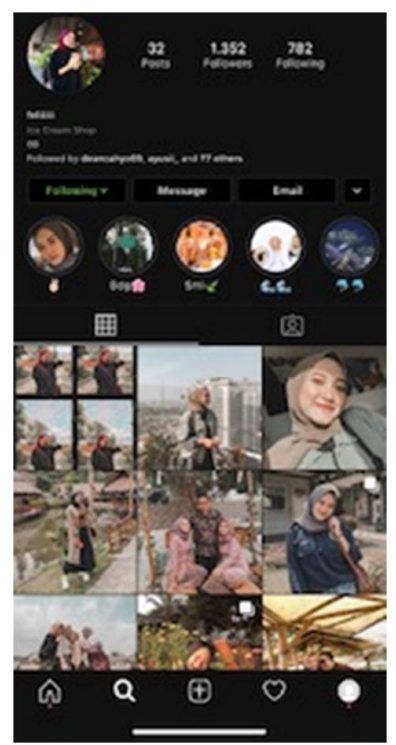

Gambar 1. Akun Instagram Informan B

Feeds Instagram merupakan hal yang penting bagi pengguna Instagram agar terlihat rapi dan menarik agar enak dilihat. Biasanya, para pengguna Instagram mengatur feedsnya dengan cara menyamaratakan warna filter yang sama atau dengan cara mengunggah foto sekilagus tiga dalam satu upload. Hal ini dilakukan agar foto yang baru diunggah tertata dengan rapi dan enak dilihat. Hal ini seperti yang diungkapkan oleh informan B ketika wawancara: "Iya aku ngatur feeds. Tujuannya ya biar enak diliatnya, rapi gitu. Aku ngatur feedsnya samain filter yang aku pakai, tapi engga yang upload sekaligus tiga gitu.” (Wawancara, 4 Maret 2020)

Para informan memilih Instagram sebagai media untuk mempresentasikan diri dikarenakan Instagram yang sangat banyak dipakai dan sangat ngetrend dibandingkan twitter atau facebook untuk mempresentasikan diri. Sering pengguna Instagram berusaha untuk menjadi terkenal atau yang sering disebut dengan istilah selebgram. Hal ini diungkapkan oleh Informan A ketika diwawancara via whatsapp:

"Iya aku pernah berusaha jadi selebgram. Pengen jugakan easy money liat kemana aja gampang gitu litanya. Pernah usaha tapi aku gagal. Dulu aku upload foto aktif banget main ig, terus apa-apa buat sg sama temen-temen yang hits eh pas lumayan banyak yang follow, terus ngerasa kaya ih yang follow banyak tapi likenya dikit. Terus aku hapusin followers yang off sampai bener bener yang kenal doang." (Wawancara via whatsapp, 03 Maret 2020).

Semakin lama, Instagram menambahkan banyak fitur untuk menarik hati penggunanya, salah satunya adalah adanya fitur face filter pada Instastory. Face filter dalam Instastory sangat popular di kalangan pengguna Instagram sekarang. Face filter terbagi dari dua jenis yaitu, filter preset atau efek berwarna dalam frame dan filter yang berbentuk emoji-emoji atau animasi kartun. Instagrammer memiliki selera tersendiri 
Community: volume 6, nomor 1, April 2020

p-ISSN: 2477-5746 e-ISSN: 2502-0544

untuk menggunakan filter yang tersedia, seperti yang dikatakan oleh Informan B ketika diwawancara: "Iya aku suka pakai filter instagram kalau buat instastory. Filter yang suka aku pakai yang jadul-jadul, coklat-coklat gitu. Kalau yang ada emoji-emojinya gitu aku jarang, jadi lebih sering yang preset gitu.” (Wawancara, 04 Maret 2020)

Dari apa yang telah diungkapkan dari ketiga informan ketika wawancara, Instagram merupakai media sosial untuk berinteraksi sesama manusia yang banyak digunakan untuk mempresentasikan diri mereka secara baik. Sesuai dengan apa yang dikatakan Goffman di dramaturginya. Dalam kehidupan terdiri dari front stage dan back stage, dimana front stage dalam penelitian ini ialah Instagram. Para pengguna Instagram menyiapkan dan menampilkan dirinya sebaik mungkin agar mendapatkan kesan yang baik terhadap orang yang melihatnya. Pada back stage, disinilah kehidupan para pengguna Instagram yang sebenarnya, apa yang diupload akan berbeda dengan kehidupan aslinya.

\section{PENUTUP}

Dipilihnya media sosial Instagram sebagai tempat presentasi diri memiliki berbagai alasan. Pertama, Instagram dipilih sebagai media untuk mempresentasikan diri karena Instagram sebuah media sosial khusus untuk video dan foto dan karena dari semua media sosial yang ada, Instagram adalah media sosial yang banyak dipakai orang dan ngetrend dibandingkan media sosial yang lainnya. Kedua, para pengguna Instagram mempresentasikan dirinya di Instagram dengan cara mengupload foto atau video ke Instagram, mengatur feeds Instagram, menggunakan filter pada Instastory dan Instalive, dan menggunakan Instastory dan Instalive untuk mempresentasikan diri.

\section{DAFTAR PUSTAKA}

Dewi, R. and Janitra, P. A. (2018) 'Dramaturgi Dalam Media Sosial: Second Account Di Instagram Sebagai Alter Ego', Jurnal Ilmu Komunikasi, 8(3), pp. 340-347.

Fitri, A. (2015) 'Dramaturgi: Pencitraan Prabowo Subianto Di Media Sosial', Jurnal Interaksi1, 4(1), pp. 101-108.

Goffman, E. (1956) The Presentation of Self in Everyday Life. Edinburgh: University of Edinburgh Social Sciences Research Centre.

Hartawan, Y. (2017) 'Media Sosial Sebagai Media Massa Dikalangan Remaja', Jurnal Retorika, 9, pp. 155-174.

Kertamukti, R. (2015) 'Instagram dan Pembentukan Citra (Studi Kualitatif Komunikasi Visual dalam Pembentukan Personal Karakter Account Instagram @basukibtp)', 
Komunikasi Profetik, 08(01), pp. 57-66.

Kertamukti, R., Nugroho, H. and Wahyono, S. B. (2019) 'Kontruksi ldentitas Melalui Stories Highlight Instagram Kalangan Kelas Menengah', Jurnal ASPIKOM, $4(1)$, p. 26.

Mutia, T. (2018) 'Generasi Milenial, Instagram dan Dramaturgi: Suatu Fonemena Dalam Penegelolaan Kesan', Komunikasiana, 1(1), pp. 38-47.

Putri, E. (2016) 'Foto Diri, Representasi Identitas Dan Masyarakat Tontonan Di Media Sosial Instagram', Jurnal Pemikiran Sosiologi, 3(1), p. 80.

Ritzer, G. and Goodman, D. J. (2012) Teori Sosiologi. Bantul: Kreasi Wacana.

Setiawan, R. (2017) 'Kebebasan Ekspresi Individual Dalam Pembangunan Manusia Era Digital', Prosiding Seminar Nasional Pendidikan FKIP UNTIRTA 2017, pp. 169-178.

Sri Suneki and Haryono (2012) 'Paradigma Teori Dramaturgi Terhadap Kehidupan Sosial', Civis, 2(2), pp. 1-11.

Sugiyono (2017) Metode Penelitian Kuantitatif, Kualitatif, dan R\&D. Bandung: Alfabeta.

Syukriardi, S. (2015) Sosiologi Komunikasi. Bandung: CV Pustaka Setia. 